\title{
Endocuff Vision is safe to use for dysplasia surveillance in patients with ulcerative colitis: a feasibility study
}

\section{(ㄷ)(1) $\ominus$}

Authors

Wendy C. Fang ${ }^{1}$, James Haridy ${ }^{1}$, Charlotte Keung ${ }^{1}$, Daniel Van Langenberg ${ }^{1,2}$, Brian P. Saunders ${ }^{3}$, Mayur Garg ${ }^{1,2}$

Institutions

1 Department of Gastroenterology, Eastern Health, Melbourne, Australia

2 Eastern Health Clinical School, Monash University, Melbourne, Australia

3 Wolfson Unit for Endoscopy, St Mark's Hospital, London, UK

submitted 18.9.2018

accepted after revision 22.1.2019

Bibliography

DOI https://doi.org/10.1055/a-0886-6421 |

Endoscopy International Open 2019; 07: E1044-E1048

(c) Georg Thieme Verlag KG Stuttgart · New York elSSN 2196-9736

Corresponding author

Dr. Mayur Garg, Eastern Health Clinical School, Monash University, Department of Gastroenterology, Eastern Health, Level 3W, Building B, 8 Arnold St, Box Hill 3128, Australia

Fax: +613-9882-2159

Mayur.Garg@monash.edu

\section{ABSTRACT}

Background and study aims Endocuff Vision improves adenoma detection rates in patients without inflammatory bowel disease. This study aimed to investigate the safety and feasibility of Endocuff Vision-assisted high-definition white light endoscopy (HDWLE) with dye-spray chromoendoscopy for detection of dysplasia in patients with ulcerative colitis.

Patients and methods Patients with clinically inactive ulcerative colitis due for dysplasia surveillance were recruited. Procedural endpoints included safety, cecal intubation rate (CIR), terminal ileum intubation rate (TIR), withdrawal time, polyp detection rate, dysplasia detection rate (DDR), and sessile serrated lesion detection rate.

Results Twenty-five patients ( 9 female, median age 57 [range 28-82] years) were studied. Endocuff Vision-assisted HDWLE was completed in all participants, with a CIR of $100 \%$, in a median 4 minutes (range $2-16$ ), and a TIR of $88 \%$ in a median of 6.5 minutes (range $3-19$ ). Median withdrawal time was 18 minutes (range $10-55$ ), including application of dye-spray, biopsies and polypectomy. The Mayo Endoscopic subscore was 0 in 11, 1 in 9, and 2 in 5 patients. The DDR was $24 \%$ ( 6 patients had a total of 12 dysplastic lesions) and sessile serrated lesion detection rate was $12 \%$ ( 3 patients had a total of 4 sessile serrated polyps). No serious adverse events occurred, with one patient developing clinically insignificant minor mucosal bleeding.

Conclusion Endocuff Vision-assisted HDWLE is feasible and safe in patients with ulcerative colitis undergoing dysplasia surveillance. Further studies are required to assess superiority of this technique compared with standard high-definition white light endoscopy with chromoendoscopy.

\section{Introduction}

Risk of developing colorectal cancer (CRC) in patients with ulcerative colitis (UC) is estimated at 1.5 to 2.4 times the background population [1,2], with most cancers arising from endoscopically visible dysplastic lesions [3,4]. Surveillance colonoscopy with dye-spray chromoendoscopy is currently recommended for detection and subsequent endoscopic removal of dysplastic lesions in patients with UC $[1,2,5]$. Furthermore, detection of CRC at an early stage via endoscopic surveillance has been demonstrated to reduce morbidity and mortality [6].
Dysplastic lesions in patients with UC are often flat and therefore more likely missed during routine inspection $[7,8]$. With evolving endoscopic technologies, miss rates for such lesions in comparison with standard-definition, white-light endoscopy (WLE) have been reduced [9-12]. Current international consensus guidelines recommend use of high-definition WLE (HDWLE) and chromoendoscopy to optimize detection of colitis-associated dysplasia [1]. Nonetheless, the cost-effectiveness of these approaches, along with precise surveillance intervals, is still poorly characterized. Improvements in techniques that enable detection and removal of dysplastic lesions, along with therapeutic developments to optimize disease control, 
may enable extension of surveillance intervals while still reducing risk of CRC.

Endocuff Vision (ARC Medical Design Ltd) is a distal colonoscopic attachment with soft, finger-like projections that aims to flatten mucosal folds and has been shown to improve adenoma detection rate (ADR) in patients without inflammatory bowel disease (IBD) undergoing CRC screening [13-18]. This device is not currently recommended in patients with severe colitis due to concerns regarding mucosal trauma [19] but has not previously been studied in patients with clinically inactive IBD undergoing surveillance colonoscopy for detection of dysplasia.

The aims of this pilot study were, therefore, to assess the safety and feasibility of Endocuff Vision-assisted HDWLE and chromoendoscopy in patients with clinically quiescent UC undergoing dysplasia surveillance.

\section{Patients and methods}

Consecutive patients with clinically inactive UC (Simple Clinical Colitis Activity Index (SCCAI) [20]<3) who met criteria for dysplasia surveillance according to national and international guidelines $[1,5,21,22]$ were invited to participate in this prospective observational study. Exclusion criteria are outlined in - Table 1.

All procedures were performed by one of two experienced colonoscopists with subspecialty interest in IBD and endoscopy, and trained in use of Endocuff Vision (MG and DvL). Patients received split-dose bowel preparation using sodium picosulfate/ magnesium oxide/citric acid (Picoprep, Fresenius Kabi Australia Pty Ltd) and macrogol/sodium sulphate/sodium chloride/potassium chloride/ascorbic acid (Glycoprep-C, Fresenius Kabi) and underwent propofol-based deep sedation administered by a specialist anesthetist. Quality of bowel preparation was graded using the Boston Bowel Preparation Scale (BBPS), a score calculated by the summation of three individual colonic segment scores (from the right, transverse, and left colon) to indicate the degree of bowel visualization [23]. Chromoendoscopy was performed during withdrawal using $0.02 \%$ methylene blue and sprayed to coat the pan-colonic mucosal surface using a foot pump.It was pre-specified that the colonoscope was to be withdrawn and Endocuff Vision removed in case of a fixed sigmoid colon with acute angulation, severe (Mayo Endoscopic Subscore 3) colitis, severe diverticulosis, identification of a new colonic stricture and/or obstructive cancer. Procedural endpoints included adverse events (including minor mucosal bleeding), cecal intubation rate (CIR) and time, terminal ileum intubation rate (TIR) and time, total withdrawal time, polyp detection rate, dysplasia detection rate, sessile serrated lesion detection rate, and requirement for removal of Endocuff Vision.

Participants were contacted by telephone to ascertain postprocedural complications including pain and rectal bleeding at days 1,7 and 21 .

\section{Role of the funding source}

This was an investigator-initiated study with an unrestricted grant from Norgine Pty Ltd, Australia. Endocuff Vision devices were provided by Norgine for free. No representatives from
- Table 1 Exclusion criteria.

Pregnancy

Known cancer or polyposis syndrome

Colonoscopy to remove known dysplastic or serrated lesion

Known colonic strictures

Known severe diverticular disease

Prior colonic resection

Clinically active UC (SCCAI $\geq 3)$

Clopidogrel, warfarin, direct-acting anticoagulants (DOACs) unable to be withheld prior to the procedure

UC, ulcerative colitis

Norgine were involved in development of the study protocol or performance, collation or analysis of data, or manuscript preparation.

\section{Statistical analysis}

Data analyses were performed using Stata v12 (StataCorp, 2011), and SPSS (22.0, IBM Corp, 2013). As this was a pilot feasibility study, a specific sample size calculation was not performed.

\section{Ethical considerations}

All subjects provided written informed consent prior to participation in the study. This study was approved by the Office of Research and Ethics at Eastern Health (LR 90/2016).

\section{Results}

Twenty-seven patients were recruited, with one patient withdrawn due to the presence of clinically active disease $(S C C A I \geq 3)$ at time of procedure and a second patient excluded from analyses due to evidence of terminal ileitis noted at the colonoscopy, requiring change of diagnosis to Crohn's disease. Patient and disease characteristics are presented in $\mathbf{~ T a b l e ~} 2$.

Endocuff Vision-assisted HDWLE was completed in all participants. Most colonoscopies were performed by a single proceduralist (MG, 23 of 25). Key outcomes are outlined in $>$ Table 3. Nineteen patients (76\%) had excellent preparation as per Boston Bowel Preparation Score (BBPS) of 9, with one patient having inadequate preparation (BBPS 3). Cecal intubation was achieved in all patients (100\%). The terminal ileum (TI) was intubated to a depth of $5 \mathrm{~cm}$ or more in 11 patients (44\%), with a short intubation able to be performed in another 11 patients, and no views of the terminal ileum in three patients.

\section{Safety}

One patient was noted to have minor superficial linear mucosal bleeding in the rectum noted upon withdrawal in a segment of Mayo 1 inflammation, with no bleeding or other clinical sequelae. No other cases of mucosal trauma were noted. Endocuff Vision did not require removal in any patient, and no inadver- 


\begin{tabular}{|c|c|}
\hline Median Age (range) & 57 years $(29-82)$ \\
\hline Female: Male & 9:16 \\
\hline Montreal Classification at diagnosis ${ }^{1}$ & $(N=25)$ \\
\hline - Disease extent: E1:E2:E3 & $4: 9: 12$ \\
\hline - Disease severity: S1:\$2:S3 & $21: 3: 1$ \\
\hline Median disease duration, y (range) & $15(8-42)$ \\
\hline Median clinic SCCAI ${ }^{2}$ (range) & $0(0-1)$ \\
\hline Median pre-procedure SCCAI (range) & $0(0-2)$ \\
\hline Previous abdominal surgery ${ }^{3}$ & $N=10$ \\
\hline \multicolumn{2}{|c|}{$\begin{array}{l}{ }^{1} \text { Montreal classification: UC disease extent: E1 - proctitis, E2 - left sided } \\
\text { colitis, E3 - extensive colitis; UC disease severity: S1 - clinical remission, } \\
\text { S2 - mild UC, S3-moderate UC, S4- severe UC. } \\
2 \text { SCCAI: Simple Clinical Colitis Activity Index } \\
{ }^{3} \text { Any previous laparoscopic or open abdominal surgery related, or not } \\
\text { related to inflammatory bowel disease }\end{array}$} \\
\hline
\end{tabular}

- Table 3 Procedural outcome measures.

\begin{tabular}{|l|l|r|}
\hline Procedural Outcomes & $\begin{array}{l}\text { Number } \\
(\mathbf{n = 2 5})\end{array}$ & $\begin{array}{l}\text { Percen- } \\
\text { tage }\end{array}$ \\
\hline Adequate bowel preparation (BBPS $\geq 6)$ & 24 & $96 \%$ \\
\hline Cecal Intubation Rate & 25 & $100 \%$ \\
\hline Terminal ileum intubation rate & 22 & $88 \%$ \\
\hline & Median & Range \\
\hline Cecal insertion time (min) & 4 & $2-16$ \\
\hline lleal insertion time (min) & 6.5 & $3-19$ \\
\hline $\begin{array}{l}\text { Withdrawal time (min), unadjusted } \\
\text { (inclusive of biopsies and polypectomy) }\end{array}$ & 18 & $10-55$ \\
\hline $\begin{array}{l}\text { Withdrawal time (min), unadjusted } \\
\text { (in patients without polypectomy) }\end{array}$ & 14 & $10-22$ \\
\hline Mayo Endoscopic Score & 1 & $0-2$ \\
\hline \begin{tabular}{l} 
BBPs, Boston bowel preparation scale \\
\hline
\end{tabular} & & \\
\hline
\end{tabular}

tent detachment occurred. No patient reported abdominal pain. One patient experienced self-limiting small volume postpolypectomy bleeding on Day 2 with no haemodynamic compromise, decline in hemoglobin or requirement for hospitalization. Endocuff Vision was deemed not to have contributed to this event. No other post-procedural bleeding was reported.

\section{Lesion detection}

Sixty-three polypoid lesions were removed in 17 patients ( $\triangle$ Table 4, Fig.1). Six patients (24\%) had 12 dysplastic lesions (tubular adenomas with low-grade dysplasia), giving a dysplastic lesion per colonoscopy rate of 0.48 . Three patients (12\%) had sessile serrated polyps.

All identified lesions were successfully resected at time of colonoscopy apart from one laterally spreading, 100-mm flat
Table 4 Resected polypoid lesions.

\begin{tabular}{|l|l|}
\hline Pathology & Number \\
\hline Tubular adenoma with LGD & 12 \\
\hline - Cecum and ascending colon & 6 \\
\hline - Transverse colon & 3 \\
\hline - Descending and sigmoid colon & 3 \\
\hline - Rectum & 0 \\
\hline - Median Size (range) & $4 \mathrm{~mm}(3-100)$ \\
\hline Tubulo-villous adenoma & 0 \\
\hline Sessile serrated polyp & 4 \\
\hline - Cecum and ascending colon & 3 \\
\hline - Transverse colon & 1 \\
\hline - Descending and sigmoid colon & 0 \\
\hline - Rectum & 0 \\
\hline - Median size (range) & $6.5 \mathrm{~mm}(4-20)$ \\
\hline Hyperplastic polyp & 20 \\
\hline - Median size (range) & $4 \mathrm{~mm} \mathrm{(2-14)}$ \\
\hline Inflammatory pseudopolyp & 1 \\
\hline Inflammatory tissue & 3 \\
\hline Normal tissue & 20 \\
\hline Polyp not retrieved & 3 \\
\hline TOTAL & \\
\hline LGD, low-grade dysplasia & \\
\hline
\end{tabular}

dysplastic lesion in the sigmoid colon, which was histologically confirmed as low-grade dysplasia on biopsy. The patient elected to undergo endoscopic resection followed by surveillance at a later date.

\section{Discussion}

Dysplastic lesions in patients with UC are typically flat and difficult to detect [7, 8]. Modern HDWLE and dye-spray chromoendoscopy have increased detection rates [9-11,24], but lesions are still missed, and surveillance intervals and cost-effectiveness remain poorly defined. This pilot study demonstrates that a distal attachment improving ADR in a non-IBD population, Endocuff Vision, is safe and feasible for use in patients with UC.

Endocuff Vision has not previously been investigated in patients with IBD, and is relatively contraindicated in severe colitis due to theoretical concerns about mucosal trauma. In this study of patients with clinically inactive UC, withdrawal of the scope and removal of Endocuff Vision if severe colitis was unexpectedly encountered was planned but not required in any of 25 patients. Endocuff Vision-assisted colonoscopy was completed in all patients. One patient with Mayo endoscopic 1 disease in the rectum was noted to have self-limited mucosal bleeding (last- 

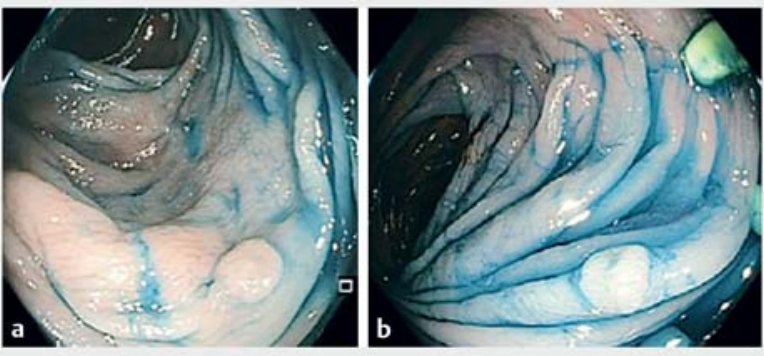

- Fig. 1 Endocuff Vision exposing sessile polypoid lesions. a Endocuff Vision flexible arms pulling mucosa down on the right, exposing a sigmoid polyp. b Endocuff Vision flexible arms interrogating adjacent mucosa to expose a sigmoid polyp.

ing less than 5 seconds) resulting from mild linear trauma, of no clinical consequence. However, eight other patients with Mayo 1 disease and five patients with Mayo 2 disease underwent the procedure without incident. Although these numbers are small, the suggestion from this cohort is that endoscopic inflammation up to Mayo 1, and probably Mayo 2, is compatible with safe use of Endocuff Vision.

Regarding other salient colonoscopic endpoints, a CIR of $100 \%$ was achieved, with a TIR of $88 \%$. Deep TI intubation was achieved in 12 of 26 patients; one of whom was excluded from analyses upon detection of Crohn's ileitis. A brief view of 2 to $3 \mathrm{~cm}$ of the TI was achieved in 11 patients, with no clear view in three, due to the flexible arms of the device. This may represent a potential limitation to use of Endocuff Vision in patients with IBD, especially those with colonic Crohn's disease, in whom assessment of the TI may be clinically important. Nonetheless, in patients with confirmed UC, the primary aim of surveillance colonoscopy is to detect dysplasia and early CRC, both of which are unaffected by lack of visualization of the TI. Insertion and withdrawal times (including pancolonic dye-spray, biopsies and polypectomy) using the device were also within the range expected with non-Endocuff Vision-assisted chromoendoscopy, meaning total colonoscopy time did not appear to be prolonged [25]. Conversely, studies in Endocuff Vision-assisted colonoscopy in patients without IBD have demonstrated similar insertion times to the current study [26-28], and thus UC per se was not associated with slower insertion using Endocuff Vision.

It must be acknowledged that this was a relatively small feasibility study, with most colonoscopies performed by a single operator. To be applicable for use by all endoscopists, larger studies with multiple operators are required. This study was not designed to assess superiority of Endocuff Vision-assisted HDWLE over conventional colonoscopy for detection of dysplastic lesions. However, dysplasia was detected in six of 25 patients, with a further three patients having sessile serrated polyps. These rates are similar or higher than previously documented for chromoendoscopy surveillance in patients with UC $[11,29,30]$. Given that dysplasia in IBD is typically flat $[7,8]$ and may be hidden behind colonic folds, and the improved ADR using Endocuff Vision in the non-IBD population [13-16,28], this device may improve detection of dysplasia in patients with IBD. To answer this question, an adequately powered controlled trial is required.

The potential value of Endocuff Vision-assisted chromoendoscopy in this population may lie in reduction in healthcare expense if future studies show improved sensitivity for detection of dysplastic lesions, and surveillance intervals can be increased through an improved negative predictive value of examinations. Sporadic adenoma detection in the same group of patients may also be enhanced. Though features that may differentiate colitis-associated dysplasia and sporadic adenomas have been described, none have been validated, and these lesions can appear similar histologically [31]. Previous histological activity predisposing to colitis-associated dysplasia may also assist, but can be difficult to determine accurately [11, 31, 32]. In this study, dysplastic lesions were not subclassified, but this may be considered on the basis of molecular markers in a future controlled comparative study. This device is far less expensive than other approaches that have been shown to confer additional efficacy such as the Endochoice Full Spectrum Endoscopy (FUSE) [33].

\section{Conclusion}

In conclusion, Endocuff Vision-assisted HDWLE with chromoendoscopy is feasible and safe in patients with UC undergoing surveillance colonoscopy, including in patients with up to mild to moderate disease activity. Further studies are required to confirm superiority of Endocuff Vision-assisted HDWLE with chromoendoscopy for detection of dysplastic lesions in patients with IBD compared with routine HDWLE with chromoendoscopy.

\section{Acknowledgements}

The authors acknowledge Norgine Pty Ltd, Australia for their support of this study.

\section{Competing interests}

Dr. Saunders has previously received an educational grant and equipment support from Arc Medical and is a paid speaker for Norgine Pty Ltd. The funding for this study was provided by Norgine Pty Ltd. The funding source had no role in the design, practice or analysis of this study.

\section{References}

[1] Laine L, Kaltenbach T, Barkun A et al. SCENIC international consensus statement on surveillance and management of dysplasia in inflammatory bowel disease. Gastroenterology 2015; 148: 639-651

[2] Farraye FA, Odze RD, Eaden J et al. AGA medical position statement on the diagnosis and management of colorectal neoplasia in inflammatory bowel disease. Gastroenterology 2010; 138: 738 - 745 
[3] Rutter MD, Saunders BP, Wilkinson KH et al. Most dysplasia in ulcerative colitis is visible at colonoscopy. Gastrointest Endosc 2004; 60: $334-339$

[4] Rubin DT, Rothe JA, Hetzel JT et al. Are dysplasia and colorectal cancer endoscopically visible in patients with ulcerative colitis? Gastrointest Endosc 2007; 65: 998 - 1004

[5] Annese V, Daperno M, Rutter MD et al. European evidence based consensus for endoscopy in inflammatory bowel disease. J Crohns Colitis 2013; 7: $982-1018$

[6] Lutgens M, Oldenburg B, Siersema P et al. Colonoscopic surveillance improves survival after colorectal cancer diagnosis in inflammatory bowel disease. $\mathrm{Br}$ J Cancer 2009; 101: 1671 - 1675

[7] Rutter M, Bernstein C, Matsumoto T et al. Endoscopic appearance of dysplasia in ulcerative colitis and the role of staining. Endoscopy 2004; 36: $1109-1114$

[8] Neumann H, Vieth M, Langner C et al. Cancer risk in IBD: how to diagnose and how to manage DALM and ALM. World J Gastroenterol 2011; 17: 3184

[9] Subramanian V, Mannath J, Ragunath K et al. Meta-analysis: the diagnostic yield of chromoendoscopy for detecting dysplasia in patients with colonic inflammatory bowel disease. Aliment Pharmacol Ther 2011; 33: $304-312$

[10] Subramanian V, Ramappa V, Telakis E et al. Comparison of high definition with standard white light endoscopy for detection of dysplastic lesions during surveillance colonoscopy in patients with colonic inflammatory bowel disease. Inflamm Bowel Dis 2012; 19: 350 - 355

[11] Rutter M, Saunders B, Schofield G et al. Pancolonic indigo carmine dye spraying for the detection of dysplasia in ulcerative colitis. Gut 2004; 53: $256-260$

[12] Choi C-HR, Rutter MD, Askari A et al. Forty-year analysis of colonoscopic surveillance program for neoplasia in ulcerative colitis: an updated overview. Am J Gastroenterol 2015; 110: 1022

[13] Patil R, Ona MA, Ofori E et al. Endocuff-assisted colonoscopy - a novel accessory in improving adenoma detection rate: a review of the literature. Clin Endosc 2016; 49: 533

[14] Floer M, Biecker E, Fitzlaff $R$ et al. Higher adenoma detection rates with endocuff-assisted colonoscopy - a randomized controlled multicenter trial. PLoS One 2014; 9: e114267

[15] Marsano J, Tzimas D, Mckinley M et al. Tu1465 Endocuff assisted colonoscopy increases adenoma detection rates: a multi-center study. Gastrointest Endosc 2014; 79: AB550

[16] Biecker E, Floer M, Heinecke A et al. Novel endocuff-assisted colonoscopy significantly increases the polyp detection rate: a randomized controlled trial. J Clin Gastroenterol 2015; 49: 413-418

[17] González-Fernández C, García-Rangel D, Aguilar-Olivos NE et al. Higher adenoma detection rate with the endocuff: a randomized trial. Endoscopy 2017; 49: 1061 - 1068

[18] Triantafyllou K, Polymeros D, Apostolopoulos P et al. Endocuff-assisted colonoscopy is associated with a lower adenoma miss rate: a multicenter randomized tandem study. Endoscopy 2017; 49: 1051 1060

[19] Medical A. Endocuff Vision Instructions for Use. In: Medical A, editor. 6th ed: Arc Medical

[20] Walmsley R, Ayres R, Pounder R et al. A simple clinical colitis activity index. Gut 1998; 43: 29-32

[21] Shergill AK, Lightdale JR, Bruining DH et al. The role of endoscopy in inflammatory bowel disease. Gastrointest Endosc 2015; 81: 1101 1121 e 1113

[22] Cancer Council Australia Colonoscopy Surveilance Working Party. Clinical Practice Guidelines for Surveillance Colonoscopy-in adenoma follow-up; following curative resection of colorectal cancer; and for cancer surveillance in inflammatory bowel disease. Cancer Council Australia; 2011

[23] Lai E], Calderwood AH, Doros G et al. The Boston bowel preparation scale: a valid and reliable instrument for colonoscopy-oriented research. Gastrointest Endosc 2009; 69: 620-625

[24] Dyson JK, Rutter MD. Colorectal cancer in inflammatory bowel disease: what is the real magnitude of the risk. World J Gastroenterol 2012; 18: 3839-3848

[25] Pohl J, Schneider A, Vogell $\mathrm{H}$ et al. Pancolonic chromoendoscopy with indigo carmine versus standard colonoscopy for detection of neoplastic lesions: a randomised two-centre trial. Gut 2011; 60: 485490

[26] Sawatzki M, Meyenberger C, Marbet UA et al. Prospective Swiss pilot study of Endocuff-assisted colonoscopy in a screening population. Endosc Int Open 2015; 3: E236

[27] Lenze F, Beyna T, Lenz P et al. Endocuff-assisted colonoscopy: a new accessory to improve adenoma detection rate? Technical aspects and first clinical experiences Endoscopy 2014; 46: 610-614

[28] Van Doorn S, Van der Vlugt M, Depla A et al. Adenoma detection with Endocuff colonoscopy versus conventional colonoscopy: a multicentre randomised controlled trial. Gut 2017; 66: 438- 445

[29] Kiesslich R, Fritsch J, Holtmann M et al. Methylene blue-aided chromoendoscopy for the detection of intraepithelial neoplasia and colon cancer in ulcerative colitis. Gastroenterology 2003; 124: 880-888

[30] Bisschops R, Bessissow T, Joseph JA et al. Chromoendoscopy versus narrow band imaging in UC: a prospective randomised controlled trial. Gut 2018; 67: 1087 - 1094

[31] Vieth M, Neumann H. Current issues in inflammatory bowel disease neoplasia. Histopathology 2015; 66: $37-48$

[32] Van Schaik FD, Offerhaus GJA, Schipper ME et al. Endoscopic and pathological aspects of colitis-associated dysplasia. Nat Rev Gastroenterol Hepatol 2009; 6: 671

[33] Leong RW, Ooi M, Corte C et al. Full-spectrum endoscopy improves surveillance for dysplasia in patients with inflammatory bowel diseases. Gastroenterology 2017; 152: 1337-1344 e1333 